lost in the delicacy of the structure of the eye and the intricacies of the ten thousand million cells of the human brain".

"If, indeed, the proper study of mankind is Man, and if (as we must agree) his behaviour and his contact with the outside world are mediated through his senses, what can be more fundamental than the study of the sense which, more than any other, determines his intelligence and regulates his conduct ...?"

To tell this story of the evolution of the eye and of vision through the animal world a vast amount of learning has been sought, assembled and arranged. It is presented in the same delightfully readable way that characterized the "Text Book of Ophthalmology". Not only is the reading easy, it seems easy to absorb the facts, and the lightness and grace of the writing tend to eliminate any text-book impression.

It is profusely and beautifully illustrated, and attractive marginal line drawings of many creatures have been added to supplement and enliven the text. The pleasant practice of opening a chapter with the photograph of, and notes about, an authority in the subject of that particular section has been carried on from the "Text Book". The layout and the production of this volume are excellent and clinicians at least will look forward eagerly to those which are planned to follow it.

Most of volume 13 of "Documenta Ophthalmologica" is given to the papers and discussion at a symposium on glaucoma held in Liège by invited participants from Europe and the United States. The papers are in English, French and German, and some of the mathematics and hydrodynamics will be beyond the ordinary ophthalmologist. But the reported work and the discussions which followed each paper provide a most interesting and instructive review of the research, basic and clinical, which in many centres is focused on aspects of the physiology and anatomy of the eye and the earliest evidences of an insidious disorder which accounts for much blindness, and which may well have its start earlier in life than has been generally thought. The last paper is an interesting, if abstruse, review of published ideas on frontal reference surfaces of binocular visual space commonly referred to as horopters.

\section{R. C. Davenport}

\section{EARLY ETHOLOGY}

\section{Instinctive Behaviour}

The Development of a Modern Concept. Translated and edited by Claire H. Schiller. Contributors : D. J. Kuenen, Konrad Lorenz, Nicholas Tinbergen, Paul H. Schiller, and Jakob von Uexkull. Pp. xix + 328. (London: Methuen and Co., Ltd., 1959.) $45 s$. net.

$\mathrm{D}$ URING the past twenty-five years very considerable progress has been made in the study of instinctive behaviour. This has been due largely to the work of Konrad Lorenz in Germany and Niko Tinbergen in Holland and England. They in turn owe some of their inspiration to a small number of earlier workers-Heinroth and von Uexkull, Whitman and Craig, J. Huxley and Eliot Howard. Their work has resulted in the development of ethologya discipline characterized not by any strict boundaries to its subject-matter (indeed most ethologists are busy attempting to establish bridgeheads with related fields such as physiology, psychology, ecology and genetics), or by a formal theory, but rather by the orienting attitudes of its research workers. These attitudes reveal the influence of a zoological background, and include an interest in problems of the function and evolution of behaviour as well as its causation, an emphasis on the importance of the description and classification of behaviour as a preliminary to analysis, and an interest in comparative studies.

"Instinctive Behaviour" is a collection of some of the earlier ethological papers, translated into English by Claire H. Schiller. As such, it is not to be taken as representative of modern ethological views, but rather as showing the sources from which they developed. The first essay, first published by von Uexkull in 1934, is concerned with the relation between an animal's perception of its environment and its sensory capacities. This relationship is obvious enough now, but needed emphasizing at the time : the paper contains a number of interesting observations, as well as some rather far-fetched speculations.

The greater part of the book consists of six essays by Lorenz, Tinbergen and Kuenen, alone or in combination, including Lorenz's (1935) "Kumpan" paper and the classic papers on the egg-rolling of the greylag goose and the begging of young thrushes. The extent of Lorenz's and Tinbergen's genius is shown by the fact that many of the ideas which have proved useful in ethology were fully developed in these essays written twenty years ago. The use of fixed action patterns in comparative study, the evolution and function of social releasers, the nature of animal language, the integration of discrete actions into functional sequences of behaviour, and many other topics are discussed here in detail ; and later workers on such subjects have had to do little more than fill in the details. At the same time, these papers contain much of the earlier theoretical background to ethology which is now discarded by most ethologists as well as by Lorenz and Tinbergen themselves. Lorenz's discussions of the innate/learning controv. ersy, releasing mechanisms or the precise nature of 'action-specific energy' make curious reading now ; though in their day they were fertile in provoking observation and experiment.

The last essay, by Lorenz, in this book (1952) contains a summary of Tinbergen's hierarchical scheme of nervous centres. This model embodied many of the earlier ethological ideas, and will probably come to mark the end of a phase in ethological thinking. Since then Lorenz and Tinbergen have developed new approaches and produced fresh ideas ; but these are not represented in this book. In their later writings the distinction between the valuable general principles on which ethological work is based on one hand, and its earlier rather loose theoretical concepts on the other, becomes apparent.

This volume was planned and begun by the late Paul H. Schiller. It contains one previously unpublished essay by him on the importance of 'innate' organization in determining the course of learning in chimpanzees, in which he emphasizes that a knowledge of this organization is essential for analysing the acquisition of skills. This paper provides an example of the way in which ethology must develop -by inter-action with other fields of study in which ethological observations and methods can be applied. 